\title{
Modeling Folding Zone in Kedungsari Compassionate Area Kulon Progo Yogyakarta with Gravity Method
}

\author{
Maya Luthfiya*, Thaqibul Fikri Niyartama \\ Physics Department, Faculty of Science and Technology, UIN Sunan Kalijaga Yogyakarta \\ J1. Marsda Adisucipto No 1 Yogyakarta 55281, Indonesia. Tel. +62-274-540971, Fax. +62-274-519739. \\ *Email: luthfiyamaya@gmail.com
}

\begin{abstract}
Luthfiya M, Niyartama T F. 2017. Modeling Folding Zone in Kedungsari Compassionate Area Kulon Progo Yogyakarta with Gravity Method. Proc Internat Conf Sci Engin 1: 19-22. This study aims to determine the condition of subsurface by doing interpretation quantitatively. Quantitative interpretation is done by modeling to determine the shape and boundary of the anomaly. The gravity data reduction is done up to Complete Bouguer Anomaly (CBA) value is obtained. The complete Bouguer anomaly is brought to horizontal plane reduction and separation of local and regional anomalies using the upward continuation method. 2.5 modelling has been made from local anomaly data to illustrate the subsurface condition of the research area more clearly. The result shows R1 density value of $2.55 \mathrm{~g} /$ $\mathrm{m} 3$ which is a limestone and R2 2,8902 $\mathrm{g} / \mathrm{m} 3$ which is andesitic rock. The position of the anticline axis is at coordinates $49 \mathrm{~S} 9128700 \mathrm{~N}$ 409844.9 E, while the syncline axis is at coordinates $9129037 \mathrm{~N} 408694,1 \mathrm{E}$.
\end{abstract}

Keywords: Gravity Modelling, Fold, Syncline, Anticline

\section{INTRODUCTION}

Activities beneath the surface of the earth become the cause of what appears on the surface of the earth. That is not flat, one of which is a fold. Fold is the deformation of the rock layers that occur as a result of the force of firmness so that the rocks move from its original position to form the curvature. In addition, the fold is a layer of skin of the earth that gets pressure in a horizontal direction. The folds can be divided into two based on the shape of the arch, the anticline and the syncline. Anticlines are the backs of the folds that incline both wings in opposite directions and away each other (concav form with a convex upward). The middle part of the anticline is called the anticline core. Sinklin is a valley of the lips that tilt both wings toward one direction and approach each other. The central part of the syncline is called the core of syncline (Park, 1997).

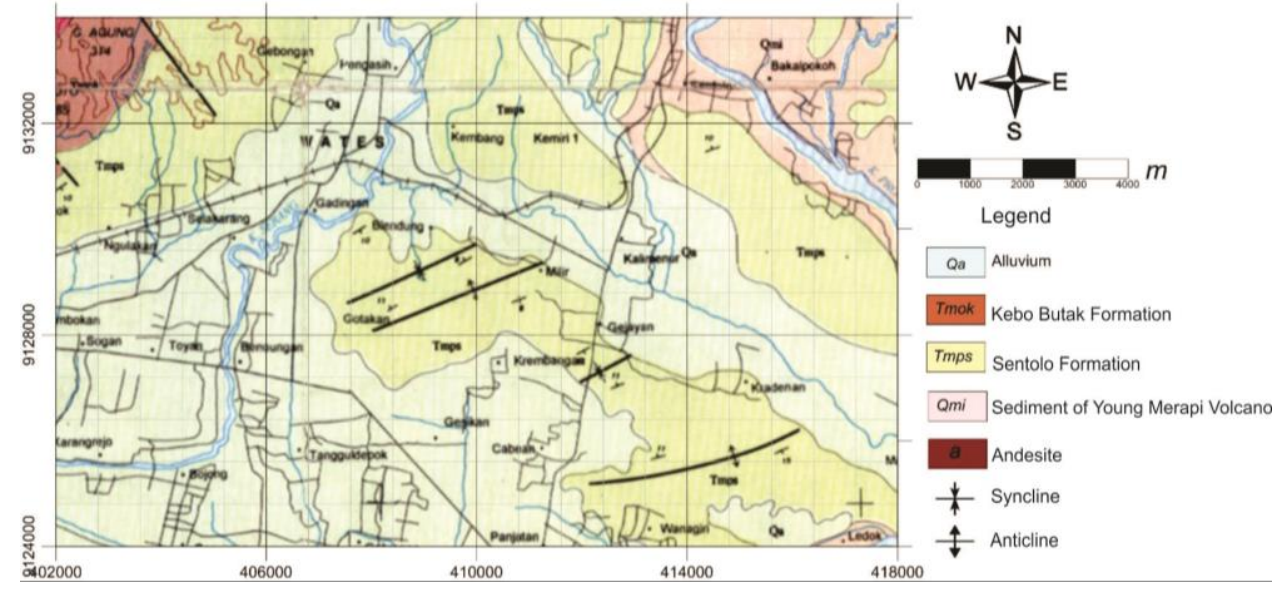

Figure 1. Regional geological maps of research areas (Rahardjo, 1995).

Based on the geological map (figure 1), fold can be found in Kedungsari Pengasih area in Kulon Progo subdistrict (Rahardjo, 1995), but the boundaries of the synclin and the anticline are not known. The existence of synclinic and anticline can be identified by measuring the value of gravity field of an area based on difference of density or mass of rock type beneath the surface of earth with gravity method (Cella, 2004). The value of the gravitational field located on the surface of the earth differs in each region and depends heavily on the solidity of the subsurface rock (Telford, 1990). 


\section{MATERIALS AND METHODS}

This research was conducted in Kedungsari Pengasih Kulon Progo Yogyakarta area, with the target of folds of synclinic and anticline using Gravity method. The data is taken as much as 44 points divided into 4 paths that direction $\mathrm{N} 315^{\circ} \mathrm{E}$. The data obtained in the form of data of observation gravity (Gobs). Subsequent Gobs data in latitude correction, free air correction, Bougeur correction, and field correction to obtain a complete bouguer anomaly (ABL). ABL data in getting still on topography so that must be done process of reduction in plane. The next process is the separation of anomalies to obtain local anomalies. This local anomaly is used for quantitative interpretation. Quantitative interpretation is done by modeling to determine the value of density of subsurface rocks. The research flow diagram can be seen in figure 2.

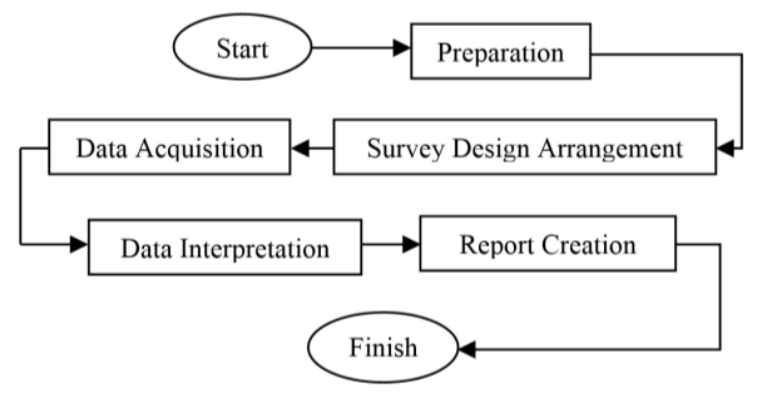

Figure 2. Flow chart of research implementation.

\section{RESULTS AND DISCUSSION}

A local anomaly map that has been overlaid on the geological map in Fig. 3 shows that there is a low anomaly pattern right at the center of the syncline structure (blue). This low pattern does not fit SW-NE leads and slightly stops at the edges, this is possible because of an unsteady anticline pattern on the part. The high anomaly pattern (red color) is found in the center of the anticline structure and SW-NE direction. The result of analysis of the pattern of high and low anomaly in gravity field data, it can be concluded that the structure of anticline and syncline is in the area, the anticline core

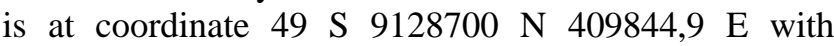
direction $\mathrm{N} 225^{\circ} \mathrm{E}$ and the syncline axis is located at coordinates $9129037 \mathrm{~N} 408694,1 \mathrm{E}$ in the same direction that is $\mathrm{N} 225^{\circ} \mathrm{E}$. The structure of anticline and syncline in the research area can be seen more clearly with the modeling of subsurface treatment.

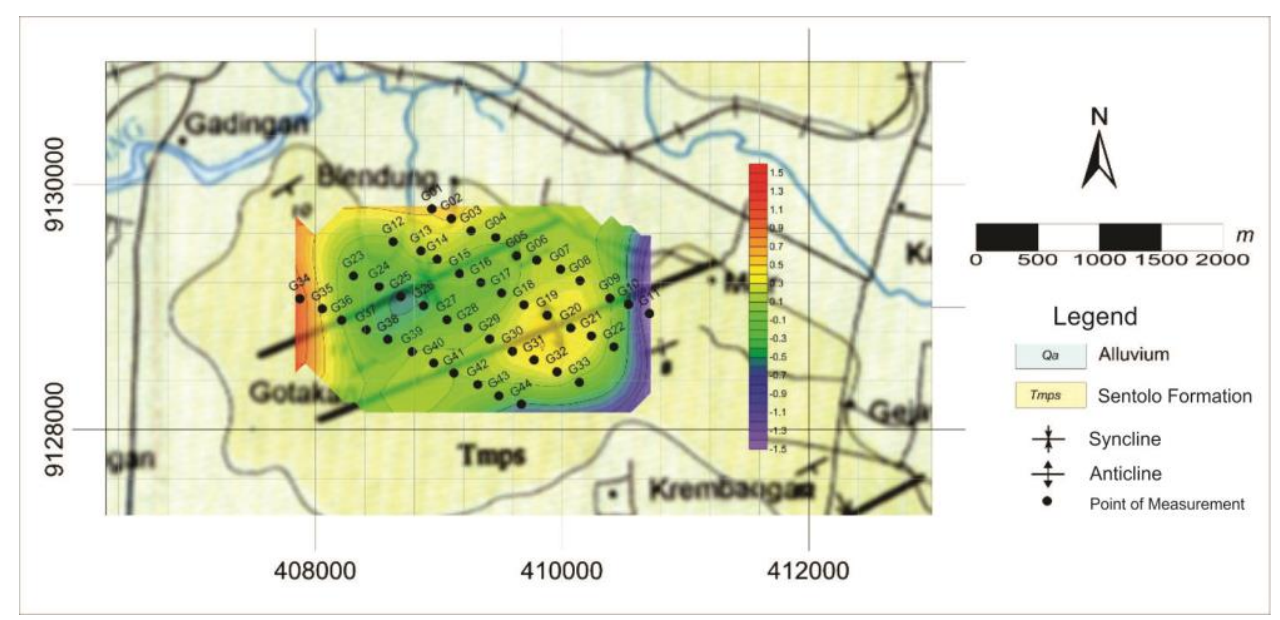

Figure 3. Geographic map overlay with contours local anomaly map.

The quantitative interpretation to obtain the shape of the subsurface is done by modeling $2.5 \mathrm{D}$ on the local anomaly map. The $2.5 \mathrm{D}$ model is a model generated from the model anomaly response approach with field anomaly response data. The local anomaly map is made in the incision as shown in Figure 4 which will be modeled below the surface. Modeling process is done by correlating local anomaly data with geological data so that get good results by using sofwere Grav2DC for windows. 


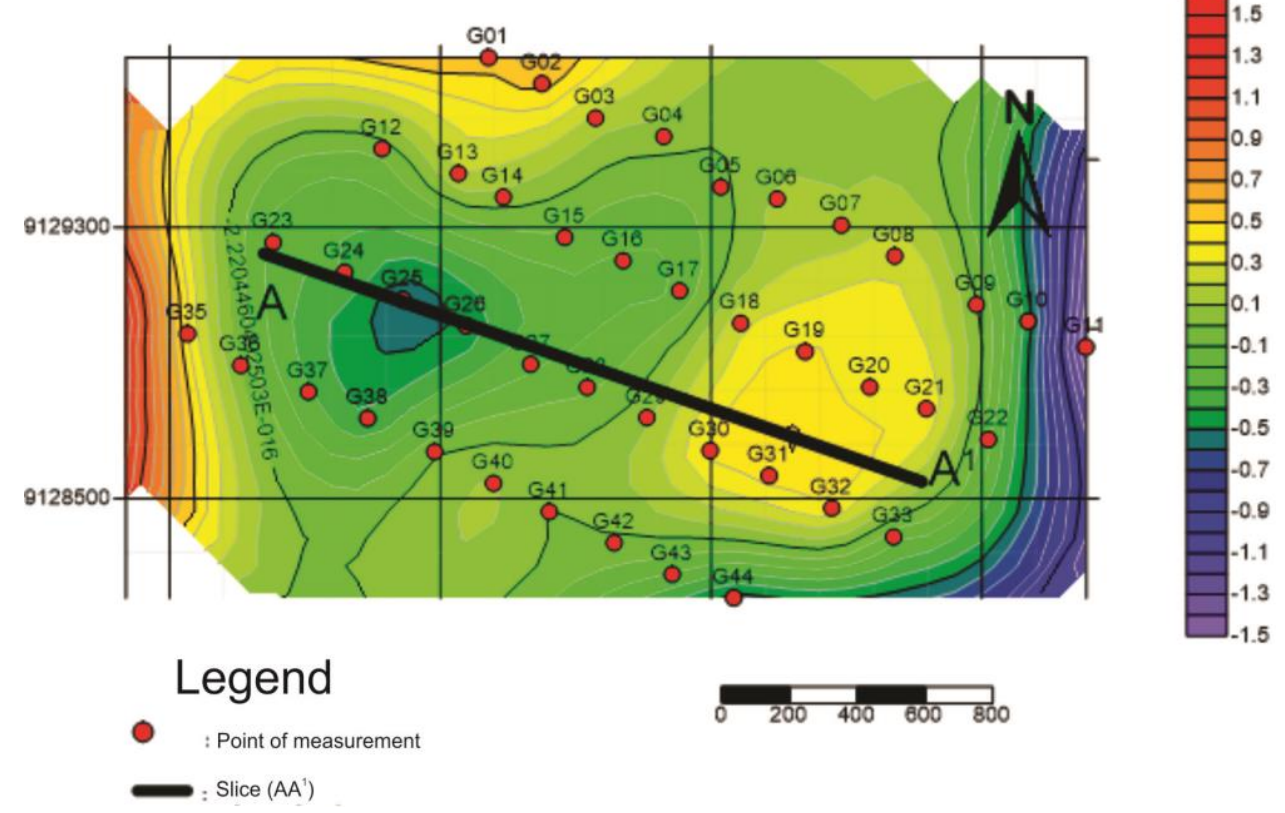

Figure 4. Incision on contours map local anomalies.

The incision is made perpendicular to the target of the research. Seen on the map of local anomalies of low anomalous patterns in the West and high anomalous patterns in the southeastern part, indicating the existence of synclinic and anticline structures. Geological map of research area shows that the research area is in Sentolo formation, Sentolo formation is composed of limestone with Bouguer density $2.67 \mathrm{~g} / \mathrm{cm} 3$.

The results of the model anomaly response approach with the field anomaly response data show the shape of the subsurface rocks and layers (figure 5), which clearly shows a high anomaly pattern which is an anticline and a low anomaly pattern in the form of a syncline, with a $\mathrm{R} 1$ density of 2,55 g / $\mathrm{m} 3$ and R2 density 2,8902 g / m3.

Rock layer R1 density of $2.55 \mathrm{~g} / \mathrm{m} 3$, based on the results of geological information analysis in the study area on the rock density table then rocks R1 identified as limestone the formation rocks Sentolo formation. The rock layer R2 has a density of $2.8902 \mathrm{~g} / \mathrm{m} 3$ which is andesitic rock (Van Bemmelen, 1949).

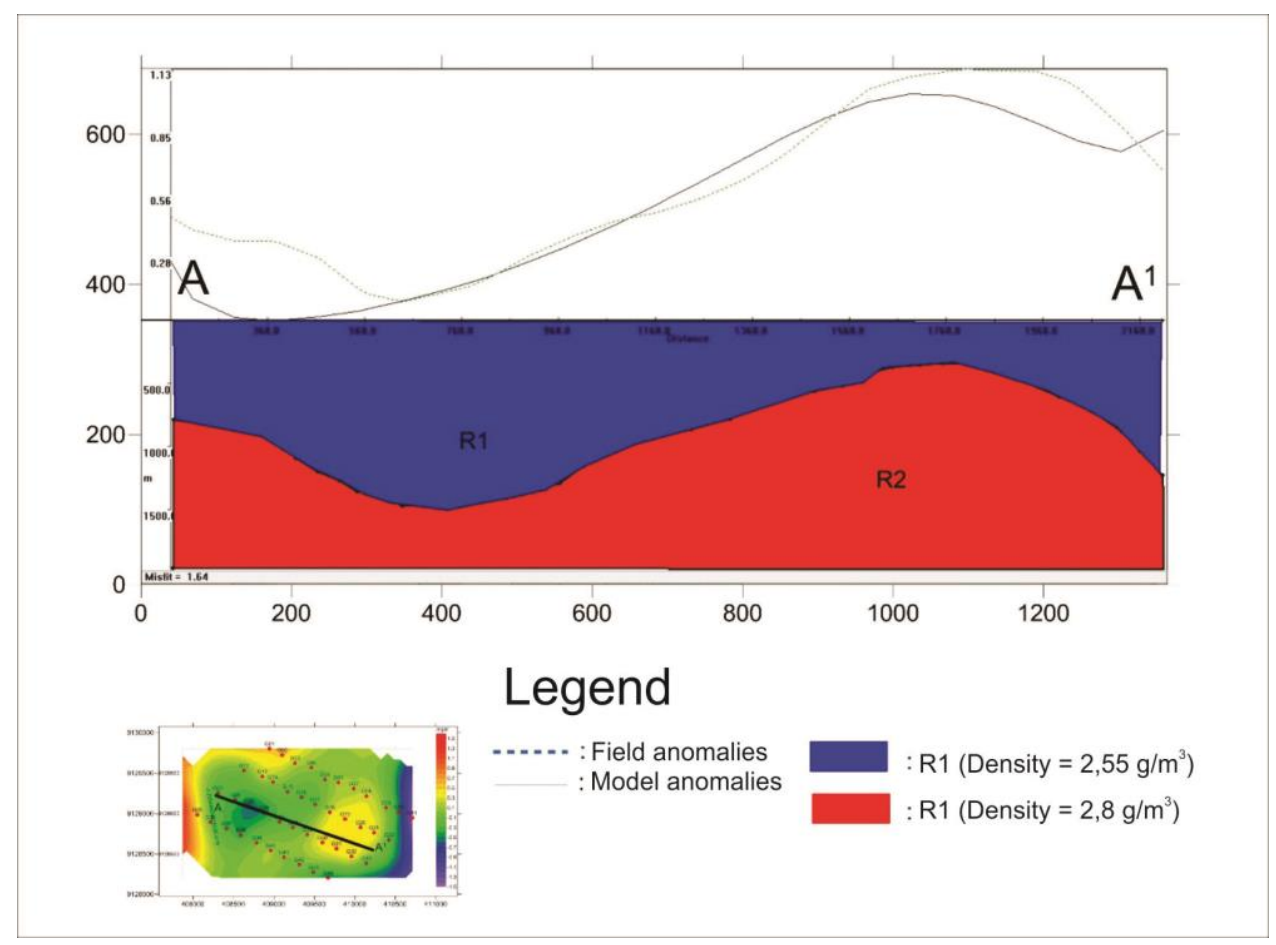

Figure 5. Model 2.5 D on AA1 Inc from local anomaly. 


\section{CONCLUSIONS}

The result shows $\mathrm{R} 1$ density value of $2.55 \mathrm{~g} / \mathrm{m} 3$ which is a limestone and R2 2,8902 g / m3 which is andesitic rock. The position of the anticline axis is at coordinates $49 \mathrm{~S} 9128700 \mathrm{~N} 409844.9 \mathrm{E}$, while the syncline axis is at coordinates $9129037 \mathrm{~N} 408694,1 \mathrm{E}$.

\section{REFERENCES}

Cella,dkk, 2004. Gravity Modelling in Fold-Thrust Belts: An Axample from The Peloritani Mountains, Southern Italy. International Geology Review, Vol. 46, 2004, p. 1042-1050.

Park, R. G. (1997) Foundation of Structural Geology. England, ISBN 978-0-74875802-9

Rahardjo, Sukandaarumidi, H, M, D, 1995," Peta Geologi Lembar Yogyakarta, Jawa, Skala 1:100.000”, $\quad$ Pusat penelitian dan pengembangan geologi.

Telford, W.N. (1990). Applied Geophysics. New York: Cambridge University Press.

Van Bemmelen, R. W. 1970. The Geology of Indonesia, volume 1. A.Haque. Netherlands 